\title{
Plasma Exo-miRNAs Correlated with AD-Related Factors of Chinese Individuals Involved in $A \beta$ Accumulation and Cognition Decline
}

Lifang WANG ( $\nabla$ wanglifang@genomics.cn )

BGI-Shenzhen: BGI Group https://orcid.org/0000-0002-6235-3069

Hefu Zhen

BGI

Yuzhe Sun

BGI

Shuang Rong

Wuhan University of Science and Technology

Benchao Li

Wuhan University of Science and Technology

Zhijie Song

BGI

Zhili Liu

BGI

Ruidong Guo

BGI

Zhiming Li

BGI-Shenzhen: BGI Group

Jiahong Ding

BGI-Shenzhen: BGI Group

Huanming Yang

BGI Group

Xun $\mathrm{Xu}$

BGI-Shenzhen: BGI Group

Xiuqing Zhang

BGI-Shenzhen: BGI Group

Haixi Sun

BGI-Shenzhen: BGI Group

Chao Nie

BGI-Shenzhen: BGI Group https://orcid.org/0000-0003-3536-0324 


\section{Research Article}

Keywords: Exosome-miRNA, AD-related factors, $A \beta$, cognition

Posted Date: November 18th, 2021

DOI: https://doi.org/10.21203/rs.3.rs-1052464/v1

License: (c) (i) This work is licensed under a Creative Commons Attribution 4.0 International License. Read Full License 


\section{Abstract}

Numerous studies have investigated the risk factors of Alzheimer's disease (AD), however, AD- risk factors related miRNAs were rarely reported. In this study, AD- risk factor related miRNAs of 119 Chinese individuals (47 AD patients and 62 cognitively normal controls) were investigated. The results showed that education, tea consumption, leisure activity, and social connection were low Body Mass Index (BMI), depression, and smoking were potentially risk factors for AD patients. Moreover, we screened exosome microRNAs (miRNAs) for the aforementioned lifestyle-related factors. Canonical correlation analyses revealed that our clinical observations were correlated with the miRNA expression profile for education, depression, leisure activity, and social connection. Furthermore, we predicted the targets of differentially expressed miRNAs and found that many of them were reported to be involved in the generation and clearance of Amyloid-beta (AB), important molecules related to cognition, and disease-activated microglia response to $A D$. Our results indicated that certain education and depression factors can contribute to $A D$ progression by modulating miRNA expression, implying that preventive interventions might alter $A D$ progression in Chinese patients.

\section{Introduction}

Alzheimer's disease (AD) is a neurodegenerative disease and causes most of patients with dementia over the world. After decades of research, there are still no effective therapy for AD. During the slow progression of $A D$, the steady cognitive and functional decline are modulated by genetic and environmental protective and risk factors, including vascular, lifestyle-related and psychological factors [1,2]. Observational studies have revealed that statistically a third of the AD cases worldwide can be attributed to the following seven commonly modifiable hazard factors: midlife hypertension, depression, diabetes mellitus, midlife obesity, low education, physical inactivity, and smoking [1,3-6]. Social integration and leisure activity have also been shown to protect against cognitive decline and dementia [7-10].

Exosomes with diameters $40-160 \mathrm{~nm}$ (average $100 \mathrm{~nm}$ ) are extracellular vesicles (EVs) derived from the late endosome [11]. They contain many cellular components including proteins, lipids, and nucleic acids (DNA, mRNAs transcripts, and non-coding RNAs (ncRNAs)), mostly miRNAs [12], and have the ability to pass through the Brain Blood Barrier (BBB) [13], making them a promising source of biomarkers to reflect the pathological process in brain. In the central nervous system (CNS), 70\% of the miRNAs released by human brain cells and possibly regulate the transcription of more than one-third of the genes $[14,15]$. Differential miRNA expression in AD patients has been observed in exosomes from the plasma [16], serum [17], and cerebrospinal fluid [18]. Recent studies have demonstrated that exosome miRNA (exomiRNA) profile can be potentially used for an early diagnosis of AD [19]. In fact, miRNA expression level could be influenced by lifestyle factors. The expression of miRNAs such as miR-935 and miR-4772 in peripheral blood mononuclear cells have been reported to be downregulated in weight loss participants under energy-restricted treatment [20]. Studies have shown that diet as a lifestyle factor that can change the miRNA expression profile in hepatocellular carcinomas [21,22] and esophageal carcinoma [23]. 
Whether AD-related lifestyle factors can change the miRNA expression profile of plasma exosome remains unreported and should be investigated.

In this study, we evaluated the miRNA expression profile in the plasma exosome Chinese patients with AD and normal individuals using next-generation sequencing data and found the correlations with AD-related factors. We found that AD-related factors, such as education, leisure activity, and depression were correlated with changes in miRNA expression. More important, many targets of these differentially expressed miRNAs were reported to modulate $A \beta$ generation and clearance, and/or important molecules involved in cognition, and disease-activated microglia response to AD.

\section{Materials And Methods}

\section{Sample information and ethics statement}

This study design included 107 Chinese participants of Han descent (47 patients with AD and 62 individuals with normal cognition) aged 60 years and older and performed miRNA expression profile analysis related to lifestyle factors. The data for the study population on sociodemographic, lifestyle variables, and history of diseases were collected by the standardized questionnaire. According to the recommendation from the National Institute on Aging-Alzheimer's Association workgroups [24], the patients with AD were screened using Mini-mental State Examination (MMSE) and then diagnosed by neurologists using a battery of tests including Clinical Dementia Rating (CDR), Geriatric Depression Scale (GDS) and Hachinski Ischemic Scale (HIS), Computerized Tomography (CT) scans for brain. The participants with Normal cognition were determined by trained interviewers using the Montreal Cognitive Assessment based on published cut-offs [25], the MMSE scores of participants with normal cognition were converted based on Montreal Cognitive Assessment (MoCA) scores according to a previous study [26]. Exosome miRNA data extracted from the blood samples of 45 patients with $A D$ and 60 cognitively normal participants were described previously (Sun et al., 2021).

\section{Assessment of baseline characteristics}

The potential influencing factors of Alzheimer's disease were collected based on previous report [27], including education, obesity, smoking, hypertension, diabetes, depression, physical inactivity, and social contact. In addition, numerous epidemiological studies also demonstrated that drinking tea, alcohol consumption, and leisure activity was associated with risks of Alzheimer's disease and dementia [28-30]. Thus, the above demographic information, lifestyle factors, and history of disease were collected in this study. Body Mass Index (BMI) was calculated as the ratio of body weight to the square of body height $\left(\mathrm{kg} / \mathrm{m}^{2},<18.5,18.5-23.9,24.0-27.9, \geq 28.0\right)$. GDS was used to assess the depression of AD patients [31]. Individuals scoring 10 or higher in GDS were considered as suffering from depression. The education levels were categorized as the no-educated (illiteracy) and educated (including elementary school, middle school, high school, and college). The tea, smoke and alcohol consumption of individuals were categorized as Yes or No. Having leisure activity was defined as participating in at least one of following 
mental items: reading, using the internet, playing cards/mahjong, calligraphy, handicrafts, watching TV, and playing chess. The social connection questionnaire included the following questions based on previous study with some details modified [32]: 1) living arrangement; 2) frequency of direct and remote contact with children; 3 ) frequency of contact with neighbors; 4) marital status. The following details were recorded: 1) living status was denoted as 1 for individuals living with family, or a live-in nurse, or in a nursing home, whereas it was denoted as 0 for individuals living alone; 2) frequency of direct and remote contact with children was denoted as 1 for individuals living with their children, had a close relationship with them, or with a contact frequency that was measurable in weeks, whereas it was denoted as 0 when the individual had a general or indifferent relationship with their children or a contact frequency that was measurable in months or years; 3 ) frequency of contact with neighbors was denoted as 1 for high frequency and 0 for medium or low frequency; 4) marital status was denoted as 1 for individuals in marriage (including remarriage), and as 0 for those not in marriage (including single, divorced, or widowed).

\section{Differential miRNA expression analyses}

miRNA expression data from a previous study were used [19]. For protective factors such as education (Fig. 1A), differentially expressed miRNAs were identified based on fold change $>1.1$ of the following ratios: NC-uneducated/NC-educated, AD-uneducated / AD-educated, and AD-uneducated / NCuneducated; or NC-educated / NC-uneducated, AD-educated/ AD-uneducated, and NC-uneducated/ ADuneducated. The same criteria were used to identify miRNAs for leisure activities (Fig. 1B), social connection (Fig. 1C).

For risk factors such as depression (Fig. 1D), miRNAs were also screened based on fold change $>1.1$ of the following ratios: NC-no depression / NC-depression, AD-no depression / AD-depression, and NC-no depression / NC-depression; or NC- no depression / NC-depression, AD-no depression / AD-depression, NC-no depression / AD-no depression. All above figures were performed by the Pheatmap package in $\mathrm{R}$ program.

\section{Statistical analyses}

In this population, 47 patients with $A D$ and 62 participants with normal cognition were performed the plasma miRNA analysis, and their basic characteristics were presented in Table 1. Canonical correlation analyses were performed to determine the correlations between lifestyle factors and expressed miRNAs specified in Table 2. The SPSS 24.0 was used for statistical analyses of the data presented in Tables 1-2. Prism 5.0 was used to perform one-way ANOVA analysis to determine the significant differences in miRNA expression for lifestyle factors such as education (Fig. 2B, 2E, 4A), leisure activity (Fig. 5B), and depression (Fig. 2F, 2I, 3A, 4D, 4G, 4H, 5A).

\section{miRNA target prediction and functional enrichment analyses}


We predicted the targets of the miRNA using the R package multiMiR (V1.10.0). Validated targets in database were selected. Predicted cut-off and limit were set to 20 and 300, respectively. Functional enrichment analyses of target genes were performed using The Database for Annotation, Visualization, and Integrated Discovery (DAVID) v6.8 [33,34] with default settings. Ten of the most enriched gene sets were selected for visualization (Fig. 2C, G, J, 3B, 4B, 4E). Mature miRNA sequences and the 3' UTR of target mRNAs were downloaded from miRbase and USUC, respectively.

\section{Results}

\section{Exo-miRNA expression profile for AD-related factors}

In order to determine whether miRNA sequencing results can provide insights to identify lifestyle factors involved in preventing $A D$, we screened the specific miRNAs related to above factors and AD by 45 ADs and 60 NCs from previous sequencing data (2 ADs and 2 NCs were excluded for miRNA screening analysis because of low quality sequencing data). Of all screened miRNAs, 8, 4, 6, 6, 12, 10 and 16 miRNAs were possibly correlated with $A D$ and education, leisure activity, social connection, regular tea consumption, BMI, habitual smoking and depression respectively (Fig. 1 and Supplemental Table 1-3). Except hsa-miR-451a that was reported to be related to depression [35,36], all specific miRNAs were novel AD-associated-factor-related miRNAs. In order to further investigate the relationship between above factors-related miRNA profiles and the clinical measurement of these factors, we performed canonical correlation analysis, which revealed that miRNA expression was correlated with clinical measurements of education $(R=0.477, P=0.01)$, depression $(R=0.605, P<0.001)$, and leisure activity $(R=0.411, P=$ 0.001) (Table 2). Therefore, observational data for education, leisure activity and depression were correlated with miRNA expression.

\section{hsa-miR-20a-5p, hsa-miR-185-5p, hsa-miR-181c-5p, and hsa-miR-502-3p were involved in A generation}

$A \beta$ was generated by the cleavage of Amyloid Protein Precursor (APP) by $\beta$-secretase to form CTF- $\beta$ (Cterminal fragment-beta), which was further cleaved by $\gamma$-secretase and then underwent several processes to form A $\beta$. $a$-secretase prevents the formation of A $\beta$ by catalyzing APP to aAPP- $\alpha$ (Alpha-cleaved APPalpha ) (Fig. 2A) [37,38]. In order to analyze the function of these miRNAs, validated targets of significantly expressed miRNAs were predicted using DAVID. A decreasing pattern in AD was alleviated by education for hsa-miR-20a-5p (Fig. 2B) that targets several genes enriched in AD (Fig. 2C), including APP (Fig. 2D) [39], which is a well-known culprit of AD [40]. Decreased expression of hsa-miR-20a-5p increased APP expression, which further promoted $A \beta$ generation, a significant signal for $A D$, which is a well-known culprit of $A D$ and an experientially validated target of miR-20a-5p [40]. Decreased expression of hsa-miR20a-5p may increase APP expression, which further promoted A $\beta$ generation, a significant signal for AD.

Presenilin 1 (PSEN1), a catalytic component of the $y$-secretase complex [41], plays a pivotal role in generating $A \beta$ and increases its expression in AD patients. hsa-miR-185-5p was a decreasing miRNA in $\mathrm{AD}$ patients and the decreasing pattern was alleviated by education (Fig. 2E) and aggravated by depression (Fig. 2F). Functional enrichment analysis showed that validated targets were enriched in AD 
(Fig. 2G). One of these targets, PSEN1, contained the predicted binding site for hsa-miR-185-5p (Fig. 2H); the same was applied to GSK3B (Glycogen Synthase Kinase 3 Beta), another key player in AD pathology, which regulates APP and PSEN1 [42]. Decreased hsa-miR-185-5p in AD improves the expression of PSEN1 and GSK3B, which further increases A $\beta$ generation.

Another decreased miRNA in AD patients was hsa-miR-181c-5p, whose decreasing pattern was aggravated by depression (Fig. 2I) and its targets were enriched in AD (Fig. 2J). Several targets of hsamiR-181c-5p had binding sites in their 3' UTRs (Fig. 2K). Breast Cancer 1 (BRCA1), which has increased expression in AD patients, was predicted to be targeted by hsa-miR-181c-5p and reported to affect the turnover of PSEN1 (Fig. 2L) [43]. Methyl-CpG Binding Protein 2 (MeCP2), which was targeted by hsa-miR181c-5p (Fig. 2K) and upregulated in AD patients, repressed a-secretase, ADAM Metallopeptidase Domain 10 (ADAM10), to improve $A \beta$ generation (Fig. 2L) [44]. Arrestin Beta 2 (ARRB2), upregulated in AD patients, as another target of hsa-miR-181c-5p, was reported to regulate $\gamma$-secretase [45]. IL1A, was expressed in $A D$ patients and directly related to $A \beta$ generation [46], with a predicted binding site in $3^{\prime}$ UTR of hsa-miR-181c-5p (Fig. 2K).

Therefore, decreased expression of hsa-miR-20a-5p in AD patients increased APP expression and decreased hsa-miR-185-5p and hsa-miR-181c-5p, thereby increasing the expression of its targets, which further upregulates $\beta$-secretase and $\gamma$-secretase and downregulates $\alpha$-secretase to increase $A \beta$ generation and plaque formation. Education was the protective factor that alleviated $A \beta$ generation, whereas depression exacerbated $A \beta$ generation (Fig. 2L).

\section{hsa-miR-20a-5p, hsa-miR-181c-5p, and hsa-miR-664a-3p, were involved in cognitive decline in Alzheimer's disease}

Brain-derived neurotrophic factor (BDNF) is well known as a beneficial marker for cognition; its deficit contributes to cognitive disorders and results in APP fragmentation [47]. A $\beta$ reduces BDNF mainly by lowering phosphorylated cyclic adenosine monophosphate (CAMP) response element binding protein (CREB) [48]. hsa-miR-664a-3p has an increased expression in AD patients, and depression intensified its upregulation (Fig. 3A). CREB1 expression was inhibited by hsa-miR-664a-3p (Fig. 3B \&C). RORA, a transcription factor that downregulates BDNF [49], was targeted by hsa-miR-181c-5p and hsa-miR-20a-5p that were correlated with depression and education, respectively (Fig. 2D \& 3D). MeCP2 can also selectively repress the expression of BDNF [44]. A decrease in the expression pattern of these two miRNAs led to an increase in the expression of RORA, which in-turn inhibited BDNF expression in AD patients. Therefore, hsa-miR-664a-3p was upregulated in AD patients, which downregulated CREB1 and BDNF expression levels, thereby leading to a cognitive decline in AD patients. hsa-miR-181c-5p and hsa-miR$20 a-5 p$ were downregulated in AD patients and targeted both the transcription factors RORA that negatively regulated BDNF as well as MeCP2 whose upregulation further reduces the level of BDNF, thereby aggravating cognitive decline in AD patients (Fig. 3E).

hsa-miR-451a, hsa-miR-27a-3p, hsa-miR-497-5p, hsa-miR-181c-5p, and hsa-miR-320a were involved in A $\beta$ clearance in Alzheimer's disease 
We found that lifestyle- and AD-related miRNAs were also involved in A clearance. Kiyota et al. (2011) injected fibroblast growth factor 2 (FGF2) into APP/PS1 mice to reveal that it significantly improved spatial learning and $A \beta$ phagocytosis [50]. The expression of hsa-miR-497-5p was upregulated in $A D$ patients and the upregulation pattern was inhibited by education (Fig. 4A). More than 20 targets of hsamiR-497-5p were enriched in AD (Fig. 4B), and FGF2 level was regulated directly by hsa-miR-497-5p (Fig. $4 C)$. Upregulated hsa-miR-497-5p in AD patients downregulated the expression of FGF2, thereby causing a decline in $A \beta$ phagocytosis (Fig. 4I).

Forkhead box 01 (FOX01), which promotes the clearance of $A \beta$, was reported to reduce the $A \beta$ level in the cortices of AD mice [51]. The expression level of hsa-miR-27a-3p was increased in AD patients and depression exacerbated such an increase (Fig. 4D). More than 10 targets of hsa-miR-27a-3p were enriched in AD (Fig. 4E). Of the 10 targets, FOX01 was directly bonded by hsa-miR-27a-3p (Fig. 4F). Upregulated hsa-miR-27a-3p in AD patients downregulated the expression of FGF2, which caused a decline in $A \beta$ clearance (Fig. 4I).

Sterol 0-acyltransferase 1 (SOAT1) inhibition has been reported to stimulate autophagy-mediated lysosomal proteolysis and increase $A \beta$ clearance [52]. miRNA hsa-miR-181c-5p was downregulated in AD patients, and their downregulation pattern was aggregated by depression (Fig. 4I). Although there was no binding site in their 3' UTRs, the two miRNAs were predicted to inhibit SOAT1 [53]. Downregulated hsamiR-181c-5p caused an increase in SOAT1 expression, thereby inhibiting autophagy-mediated lysosomal proteolysis and $A \beta$ clearance (Fig. 4I).

Aquaporin 4 (AQP4) is involved in $A \beta$ clearance through the glymphatic pathway. $A D$ led to a loss of polarity of AQP4 at the astrocytic endfeet, thereby causing more $A \beta$ deposition because of a dysfunction in the glymphatic system [54]. AQP4 was predicted to be inhibited by hsa-miR-320a, which is increased by depression in AD patients (Fig. $4 \mathrm{H}$ ). Reduced AQP4 possibly increased $A \beta$ deposition owing to $a$ dysfunction of the glymphatic system (Fig. 4I).

Metalloproteins, MMP2 and MMP9, have been reported to cleave soluble and fibrillar forms of A [55]. MMP2 and MMP9 [56] were targeted by hsa-miR-451a, which was decreased by depression in AD patients (Fig. 4I). It is possible that an increase in MMP2 and MMP9 facilitates the cleavage of $A \beta$; however, it cannot keep up with the speed of $A \beta$ accumulation in $A D$ patients.

\section{Other miRNAs related to AD-related factors}

There were two more miRNAs that were correlated with $A D$ and lifestyle factors, even though no validated targets were identified so far. hsa-miR-23b-3p was upregulated in $A D$ patients, and the upregulating pattern was enhanced by depression (Fig. 5A). hsa-miR-502-3p was also upregulated in AD patients; however, this expression pattern was alleviated by leisure activity (Fig. 5B). Loss of TREM2 (Triggering Receptor Expressed On Myeloid Cells 2) function compromises the microglial response (the diseaseactivated microglia pattern) to the accumulation of $A \beta$ [57]. Skipping the transcription of exon 3 of TREM2 causes nonsense-mediated mRNA decay, thereby causing a reduction in functional TREM2 in AD 
patients. CELF2 (CUGBP Elav-Like Family Member 2) has been linked to the exon3 transcription skipping, and its overexpression enhances TREM2 exon3 skipping [58]. hsa-miR-185-5p was downregulated in AD patients (Fig. 2E, F), which promoted CELF2 expression (Fig. 5C). Therefore, a decrease in the expression level of hsa-miR-185-5p in AD patients was enhanced by depression and reduced by education, thereby promoting its target CELF2, which reduced the TREM2 function in the microglia and further increased $A \beta$ accumulation (Fig. 5D).

\section{Discussion}

Our study found that several AD-related factors, including education, leisure-time mental activity, and depression were correlated to miRNA expression. Compared to normal cognition group, a decreased expression pattern of hsa-miR-185-5p in AD group was enhanced by depression and alleviated by education significantly, this miRNA was involved in $A \beta$ generation (Fig. 2L) and accumulation (Fig. 5D). hsa-miR-181c-5p, which is a depression and AD-related miRNA (Fig. 2l), was involved in A $\beta$ generation (Fig. 2L), cognitive decline (Fig. 3E), and Aßclearance (Fig. 4I). hsa-miR-20a-5p, which was decreased in $A D$ patients, was alleviated in people educated and involved in $A \beta$ generation (Fig. $2 \mathrm{~L}$ ) and cognitive decline (Fig. 3E).

To our knowledge, this is the first report to correlate clinical observations with miRNAs expression profiles in $A D$ and $A D$ - related factors. In this study, our results provide new insight on how lifestyle- and ADrelated miRNAs promote AD progression through validated targets. APP and PSEN1 are critical molecules for process of $A \beta$ accumulation, the mainstream hypothesis for AD [37,38]. APP was one target of hsamiR-20a-5p, reduced expression pattern of hsa-miR-20a-5p in AD patients improves APP expression, the subtract of $A \beta$. The decreasing expression pattern of hsa-miR-20a-5p in AD was alleviated in educated people. Presenilin 1 (PSEN1) is a catalytic component of the $y$-secretase complex [41], and plays a pivotal role in generating $A \beta$ and increases its expression in AD patients. PSEN1 is a target of hsa-miR-185-5p, a decreasing miRNA in $A D$ patients. And its decreasing expression pattern was alleviated by education (Fig. $2 \mathrm{E}$ ) and aggravated by depression (Fig. 2F). Besides, BDNF is a beneficial molecule for cognition and its expression level decreases in $A D$ patient because of $A \beta$ accumulation [48]. Several molecules influence BDNF expression directly including CREB1, MeCP2, and RORA, which were targeted by hsa-miR-664a-3p, hsa-miR-181c-5p, and hsa-miR-20a-5p (Fig. 3E). The expression pattern of above three miRNAs in AD patients caused BDNF deficiency through validated targets, and the miRNA expression trends were alleviated by education and aggregated by depression.

Interestingly, the targets of our miRNAs are also enriched in various types of cancers. In fact, miRNAs participate in conducting and regulating many cellular processes such as proliferation, apoptosis, differentiation, metabolism, and immunity [59-64]. Abnormal miRNA expression is usually related to diseases such as cancers [65,66], AD [67], and the coronavirus pandemic [68,69]. Based on the miRNA expression panels, there is a hypothesis that $A D$ and cancer (hematologic malignancies, colorectal, and lung cancer) are characterized by a shift in the expression of the same genes but in the opposite direction, which is supported by several reports [70-74]. Stánitz et al. [75,76] reported lifestyle-related 
miRNA profile in gastric cancer and esophageal cancer samples. In gastric cancer samples, upregulated expression of miR-21 was related to low social status and habitual smoking, and the downregulation of miR-143 was related to habitual smoking. In esophageal cancer samples, increased expression of miR205 was related to smoking, and reduced expression of miR-143 and miR-203 were related to low social status and smoking. Therefore, it is interesting to study the lifestyle factors involved in AD and cancer in future studies.

\section{Limitations}

There were some limitations for the samples of miRNA expression used in this study, although our sample size $(n=105)$ did provide insights into AD-related factors. For example, only one person was educated and suffered from AD, while no NCs suffered from depression (Table 1), these limitations indicate a scope for further study in this area. Moreover, although the validated targets of specific miRNA were predicted in this study, transcriptome or proteome would be used for validation and more information in our further research. Nevertheless, another validated group should be used for further validation for the specifically expressed miRNA and verifying the potential biomarkers for the AD -related lifestyle factors in our future study.

\section{Conclusion}

In this study, we first reported AD and education /depression-related miRNAs. Specific expressed miRNAs were reported to be correlated with AD related factors, such as hsa-miR-185-5p, hsa-miR-20a-5p, hsa-miR181c-5p and hsa-miR-497-5p. Besides, the predicted targets of these miRNAs were indicated to take part in $A \beta$ generation and clearance, cognitive decline, and progression of $A D$. These findings provided clues of $A D$ preventive interventions in Chinese people.

\section{Declarations}

Ethics approval and consent to participate

All participants were approved by the BGI IRB (BGI-IRB 20149) and the Medical Ethics Committee of Medical College, Wuhan University of Science and Technology (20190049), and each of them provided informed consent before sample collection, and all samples were anonymized before further analysis.

\section{Consent for publication}

Not applicable.

\section{Availability of data and materials}

The datasets used and/or analyzed during the current study are available from the corresponding author on reasonable request. 


\section{Competing Interests}

The authors declare no competing financial interests.

\section{Author Contributions}

L. W., C. N. and H. S. designed the research; L. W. analyzed bioinformatic data; L. W. analyzed the clinical observational data, H. Z., Y. S. and C. N. provided the sequencing data, S. R. and B. L. provided the clinical observational data and advices, Z. S., Z. L., and R. G. contributed unpublished reagents/analytic tools; Z. L., J. D., H. Y., X. X., and X. Z provided unpublished advices; L. W. wrote the paper. All the authors read and approved the final manuscript.

\section{Funding}

This research was supported by the National Key Research and Development Program of China (No. 2020YFC2002902), National Science Foundation for Young Scientists of China (Grant No. 31900397), Science, Technology and Innovation Commission of Shenzhen Municipality under Grant No. JCYJ20170412153100794 and No. JCYJ20180507183615145, and National Natural Science Foundation of China (No. 81941016).

\section{References}

1. Kivipelto M, Mangialasche F, Ngandu T (2018) Lifestyle interventions to prevent cognitive impairment, dementia and Alzheimer disease. Nat Rev Neurol 14 (11):653-666. doi:10.1038/s41582-018-0070-3

2. Solomon A, Mangialasche F, Richard E, Andrieu S, Bennett DA, Breteler M, Fratiglioni L, Hooshmand B, Khachaturian AS, Schneider LS, Skoog I, Kivipelto M (2014) Advances in the prevention of Alzheimer's disease and dementia. J Intern Med 275 (3):229-250. doi:10.1111/joim.12178

3. Norton S, Matthews FE, Barnes DE, Yaffe K, Brayne C (2014) Potential for primary prevention of Alzheimer's disease: an analysis of population-based data. Lancet Neurol 13 (8):788-794. doi:10.1016/S1474-4422(14)70136-X

4. Deckers K, van Boxtel MPJ, Schiepers OJG, de Vugt M, Muñoz Sánchez JL, Anstey KJ, Brayne C, Dartigues J-F, Engedal K, Kivipelto M, Ritchie K, Starr JM, Yaffe K, Irving K, Verhey FRJ, Köhler S (2015) Target risk factors for dementia prevention: a systematic review and Delphi consensus study on the evidence from observational studies. Int J Geriatr Psychiatry 30 (3):234-246. doi:10.1002/gps.4245

5. Jia L, Du Y, Chu L, Zhang Z, Li F, Lyu D, Li Y, Li Y, Zhu M, Jiao H, Song Y, Shi Y, Zhang H, Gong M, Wei C, Tang Y, Fang B, Guo D, Wang F, Zhou A, Chu C, Zuo X, Yu Y, Yuan Q, Wang W, Li F, Shi S, Yang H, Zhou C, Liao Z, Lv Y, Li Y, Kan M, Zhao H, Wang S, Yang S, Li H, Liu Z, Wang Q, Qin W, Jia J, Group C (2020) Prevalence, risk factors, and management of dementia and mild cognitive impairment in adults aged 60 
years or older in China: a cross-sectional study. Lancet Public Health 5 (12):e661-e671. doi:10.1016/S2468-2667(20)30185-7

6. Hao L, Xing Y, Li X, Mu B, Zhao W, Wang G, Wang T, Jia J, Han Y (2019) Risk Factors and Neuropsychological Assessments of Subjective Cognitive Decline (plus) in Chinese Memory Clinic. Front Neurosci 13:846. doi:10.3389/fnins.2019.00846

7. Fratiglioni L, Paillard-Borg S, Winblad B (2004) An active and socially integrated lifestyle in late life might protect against dementia. Lancet Neurol 3 (6):343-353

8. Marioni RE, Proust-Lima C, Amieva H, Brayne C, Matthews FE, Dartigues J-F, Jacqmin-Gadda H (2015) Social activity, cognitive decline and dementia risk: a 20-year prospective cohort study. BMC Public Health 15:1089. doi:10.1186/s12889-015-2426-6

9. Wang Z, Marseglia A, Shang Y, Dintica C, Patrone C, Xu W (2020) Leisure activity and social integration mitigate the risk of dementia related to cardiometabolic diseases: A population-based longitudinal study. Alzheimers Dement 16 (2):316-325. doi:10.1016/j.jalz.2019.09.003

10. Ma YH, Wang YY, Tan L, Xu W, Shen XN, Wang HF, Hou XH, Cao XP, Bi YL, Dong Q, Yang JL, Yu JT (2021) Social Networks and Cerebrospinal Fluid Biomarkers of Alzheimer's Disease Pathology in Cognitively Intact Older Adults: The CABLE Study. J Alzheimers Dis 81 (1):263-272. doi:10.3233/jad201426

11. Kalluri R, LeBleu VS (2020) The biology, function, and biomedical applications of exosomes. Science 367 (6478). doi:10.1126/science.aau6977

12. D'Anca M, Fenoglio C, Serpente M, Arosio B, Cesari M, Scarpini EA, Galimberti D (2019) Exosome Determinants of Physiological Aging and Age-Related Neurodegenerative Diseases. Frontiers in aging neuroscience 11:232. doi:10.3389/fnagi.2019.00232

13. Otero-Ortega L, Laso-García F, Gómez-de Frutos M, Fuentes B, Diekhorst L, Díez-Tejedor E, GutiérrezFernández M (2019) Role of Exosomes as a Treatment and Potential Biomarker for Stroke. Transl Stroke Res 10 (3):241-249. doi:10.1007/s12975-018-0654-7

14. Nowak JS, Michlewski G (2013) miRNAs in development and pathogenesis of the nervous system. Biochem Soc Trans 41 (4):815-820. doi:10.1042/BST20130044

15. Kosik KS (2006) The neuronal microRNA system. Nat Rev Neurosci 7 (12):911-920

16. Lugli G, Cohen AM, Bennett DA, Shah RC, Fields CJ, Hernandez AG, Smalheiser NR (2015) Plasma Exosomal miRNAs in Persons with and without Alzheimer Disease: Altered Expression and Prospects for Biomarkers. PLoS ONE 10 (10):e0139233. doi:10.1371/journal.pone.0139233 
17. Cheng L, Doecke JD, Sharples RA, Villemagne VL, Fowler CJ, Rembach A, Martins RN, Rowe CC, Macaulay SL, Masters CL, Hill AF (2015) Prognostic serum miRNA biomarkers associated with Alzheimer's disease shows concordance with neuropsychological and neuroimaging assessment. Mol Psychiatry 20 (10):1188-1196. doi:10.1038/mp.2014.127

18. Gui Y, Liu H, Zhang L, Lv W, Hu X (2015) Altered microRNA profiles in cerebrospinal fluid exosome in Parkinson disease and Alzheimer disease. Oncotarget 6 (35):37043-37053.

doi:10.18632/oncotarget.6158

19. Sun Y, Zhen H, Wang L, Li B, Song Z, Deng Y, Liu Z, Ding J, Li T, Zhang W, Nie C, Rong S (2021) Plasma exosomal miRNA analysis of Alzheimer's disease reveals the dysfunction of a neural network. bioRxiv. doi:https://doi.org/10.1101/2021.04.12.439575

20. Milagro FI, Miranda J, Portillo MP, Fernandez-Quintela A, Campión J, Martínez JA (2013) Highthroughput sequencing of microRNAs in peripheral blood mononuclear cells: identification of potential weight loss biomarkers. PLoS ONE 8 (1):e54319. doi:10.1371/journal.pone.0054319

21. Davis CD, Ross SA (2008) Evidence for dietary regulation of microRNA expression in cancer cells. Nutr Rev 66 (8):477-482. doi:10.1111/j.1753-4887.2008.00080.x

22. Kutay H, Bai S, Datta J, Motiwala T, Pogribny I, Frankel W, Jacob ST, Ghoshal K (2006)

Downregulation of miR-122 in the rodent and human hepatocellular carcinomas. Journal of cellular biochemistry 99 (3):671-678. doi:10.1002/jcb.20982

23. Stánitz É, Juhász K, Gombos K, Gőcze K, Tóth C, Kiss I (2015) Alteration of miRNA expression correlates with lifestyle, social and environmental determinants in esophageal carcinoma. Anticancer Res 35 (2):1091-1097

24. McKhann GM, Knopman DS, Chertkow H, Hyman BT, Jack CR, Jr., Kawas CH, Klunk WE, Koroshetz WJ, Manly JJ, Mayeux R, Mohs RC, Morris JC, Rossor MN, Scheltens P, Carrillo MC, Thies B, Weintraub S, Phelps CH (2011) The diagnosis of dementia due to Alzheimer's disease: recommendations from the National Institute on Aging-Alzheimer's Association workgroups on diagnostic guidelines for Alzheimer's disease. Alzheimers Dement 7 (3):263-269. doi:10.1016/j.jalz.2011.03.005

25. Lu J, Li D, Li F, Zhou A, Wang F, Zuo X, Jia XF, Song H, Jia J (2011) Montreal cognitive assessment in detecting cognitive impairment in Chinese elderly individuals: a population-based study. J Geriatr Psychiatry Neurol 24 (4):184-190. doi:10.1177/0891988711422528

26. Huang YY, Qian SX, Guan QB, Chen KL, Zhao QH, Lu JH, Guo QH (2021) Comparative study of two Chinese versions of Montreal Cognitive Assessment for Screening of Mild Cognitive Impairment. Appl Neuropsychol Adult 28 (1):88-93. doi:10.1080/23279095.2019.1602530 
27. Livingston G, Sommerlad A, Orgeta V, Costafreda SG, Huntley J, Ames D, Ballard C, Banerjee S, Burns A, Cohen-Mansfield J, Cooper C, Fox N, Gitlin LN, Howard R, Kales HC, Larson EB, Ritchie K, Rockwood K, Sampson EL, Samus Q, Schneider LS, Selbaek G, Teri L, Mukadam N (2017) Dementia prevention, intervention, and care. Lancet 390 (10113):2673-2734. doi:10.1016/S0140-6736(17)31363-6

28. Schwarzinger M, Pollock BG, Hasan OSM, Dufouil C, Rehm J, QalyDays Study G (2018) Contribution of alcohol use disorders to the burden of dementia in France 2008-13: a nationwide retrospective cohort study. Lancet Public Health 3 (3):e124-e132. doi:10.1016/S2468-2667(18)30022-7

29. Kakutani S, Watanabe H, Murayama N (2019) Green Tea Intake and Risks for Dementia, Alzheimer's Disease, Mild Cognitive Impairment, and Cognitive Impairment: A Systematic Review. Nutrients 11 (5). doi:10.3390/nu11051165

30. Yu JT, Xu W, Tan CC, Andrieu S, Suckling J, Evangelou E, Pan A, Zhang C, Jia J, Feng L, Kua EH, Wang YJ, Wang HF, Tan MS, Li JQ, Hou XH, Wan Y, Tan L, Mok V, Tan L, Dong Q, Touchon J, Gauthier S, Aisen PS, Vellas B (2020) Evidence-based prevention of Alzheimer's disease: systematic review and metaanalysis of 243 observational prospective studies and 153 randomised controlled trials. J Neurol Neurosurg Psychiatry 91 (11):1201-1209. doi:10.1136/jnnp-2019-321913

31. Cruice M, Worrall L, Hickson L (2011) Reporting on psychological well-being of older adults with chronic aphasia in the context of unaffected peers. Disability and rehabilitation 33 (3):219-228. doi:10.3109/09638288.2010.503835

32. Wang Z, Marseglia A, Shang Y, Dintica C, Patrone C, Xu W (2020) Leisure activity and social integration mitigate the risk of dementia related to cardiometabolic diseases: A population-based longitudinal study. Alzheimers Dement 16 (2):316-325. doi:10.1016/j.jalz.2019.09.003

33. Huang da W, Sherman BT, Lempicki RA (2009) Systematic and integrative analysis of large gene lists using DAVID bioinformatics resources. Nat Protoc 4 (1):44-57. doi:10.1038/nprot.2008.211

34. Huang da W, Sherman BT, Lempicki RA (2009) Bioinformatics enrichment tools: paths toward the comprehensive functional analysis of large gene lists. Nucleic Acids Res 37 (1):1-13. doi:10.1093/nar/gkn923

35. Camkurt MA, Acar Ş, Coşkun S, Güneş M, Güneş S, Yılmaz MF, Görür A, Tamer L (2015) Comparison of plasma MicroRNA levels in drug naive, first episode depressed patients and healthy controls. Journal of psychiatric research 69:67-71. doi:10.1016/j.jpsychires.2015.07.023

36. Wan Y, Liu Y, Wang X, Wu J, Liu K, Zhou J, Liu L, Zhang C (2015) Identification of differential microRNAs in cerebrospinal fluid and serum of patients with major depressive disorder. PLoS ONE 10 (3):e0121975. doi:10.1371/journal.pone.0121975 
37. De-Paula VJ, Radanovic M, Diniz BS, Forlenza OV (2012) Alzheimer's disease. Sub-cellular biochemistry 65:329-352. doi:10.1007/978-94-007-5416-4_14

38. Peron R, Vatanabe IP, Manzine PR, Camins A, Cominetti MR (2018) Alpha-Secretase ADAM10 Regulation: Insights into Alzheimer's Disease Treatment. Pharmaceuticals (Basel, Switzerland) 11 (1). doi:10.3390/ph11010012

39. Hébert SS, Horré K, Nicolaï L, Bergmans B, Papadopoulou AS, Delacourte A, De Strooper B (2009) MicroRNA regulation of Alzheimer's Amyloid precursor protein expression. Neurobiol Dis 33 (3):422-428. doi:10.1016/j.nbd.2008.11.009

40. O'Brien RJ, Wong PC (2011) Amyloid precursor protein processing and Alzheimer's disease. Annual review of neuroscience 34:185-204. doi:10.1146/annurev-neuro-061010-113613

41. Zoltowska KM, Berezovska O (2018) Dynamic Nature of presenilin1/Y-Secretase: Implication for Alzheimer's Disease Pathogenesis. Molecular neurobiology 55 (3):2275-2284. doi:10.1007/s12035-0170487-5

42. Lauretti E, Dincer O, Praticò D (2020) Glycogen synthase kinase-3 signaling in Alzheimer's disease. Biochimica et biophysica acta Molecular cell research 1867 (5):118664. doi:10.1016/j.bbamcr.2020.118664

43. Wezyk M, Zekanowski C (2018) Role of BRCA1 in Neuronal Death in Alzheimer's Disease. ACS chemical neuroscience 9 (5):870-872. doi:10.1021/acschemneuro.8b00149

44. Kim B, Choi Y, Kim HS, Im HI (2019) Methyl-CpG Binding Protein 2 in Alzheimer Dementia. International neurourology journal 23 (Suppl 2):S72-81. doi:10.5213/inj.1938196.098

45. Thathiah A, Horré K, Snellinx A, Vandewyer E, Huang Y, Ciesielska M, De Kloe G, Munck S, De Strooper $B(2013) \beta$-arrestin 2 regulates A $\beta$ generation and $\gamma$-secretase activity in Alzheimer's disease. Nature medicine 19 (1):43-49. doi:10.1038/nm.3023

46. Mrak RE, Griffin WS (2001) Interleukin-1, neuroinflammation, and Alzheimer's disease. Neurobiology of aging 22 (6):903-908. doi:10.1016/s0197-4580(01)00287-1

47. Wang ZH, Xiang J, Liu X, Yu SP, Manfredsson FP, Sandoval IM, Wu S, Wang JZ, Ye K (2019) Deficiency in BDNF/TrkB Neurotrophic Activity Stimulates $\delta$-Secretase by Upregulating C/EBP $\beta$ in Alzheimer's Disease. Cell reports 28 (3):655-669.e655. doi:10.1016/j.celrep.2019.06.054

48. Amidfar M, de Oliveira J, Kucharska E, Budni J, Kim YK (2020) The role of CREB and BDNF in neurobiology and treatment of Alzheimer's disease. Life sciences 257:118020.

doi:10.1016/j.Ifs.2020.118020 
49. Acquaah-Mensah GK, Agu N, Khan T, Gardner A (2015) A regulatory role for the insulin- and BDNFlinked RORA in the hippocampus: implications for Alzheimer's disease. J Alzheimers Dis 44 (3):827-838. doi:10.3233/jad-141731

50. Kiyota T, Ingraham KL, Jacobsen MT, Xiong H, Ikezu T (2011) FGF2 gene transfer restores hippocampal functions in mouse models of Alzheimer's disease and has therapeutic implications for neurocognitive disorders. Proc Natl Acad Sci U S A 108 (49):E1339-1348. doi:10.1073/pnas.1102349108

51. Zhang W, Bai S, Yang J, Zhang Y, Liu Y, Nie J, Meng D, Shi R, Yao Z, Wang M, Wang H, Li C (2020) FoxO1 overexpression reduces $A \beta$ production and tau phosphorylation in vitro. Neuroscience letters 738:135322. doi:10.1016/j.neulet.2020.135322

52. Shibuya Y, Chang CC, Huang LH, Bryleva EY, Chang TY (2014) Inhibiting ACAT1/SOAT1 in microglia stimulates autophagy-mediated lysosomal proteolysis and increases Aß1-42 clearance. J Neurosci 34 (43):14484-14501. doi:10.1523/jneurosci.2567-14.2014

53. Helwak A, Kudla G, Dudnakova T, Tollervey D (2013) Mapping the human miRNA interactome by CLASH reveals frequent noncanonical binding. Cell 153 (3):654-665. doi:10.1016/j.cell.2013.03.043

54. Mader S, Brimberg L (2019) Aquaporin-4 Water Channel in the Brain and Its Implication for Health and Disease. Cells 8 (2). doi:10.3390/cells8020090

55. Terni B, Ferrer I (2015) Abnormal Expression and Distribution of MMP2 at Initial Stages of Alzheimer's Disease-Related Pathology. J Alzheimers Dis 46 (2):461-469. doi:10.3233/jad-142460

56. Nan Y, Han L, Zhang A, Wang G, Jia Z, Yang Y, Yue X, Pu P, Zhong Y, Kang C (2010) MiRNA-451 plays a role as tumor suppressor in human glioma cells. Brain research 1359:14-21.

doi:10.1016/j.brainres.2010.08.074

57. Zhou Y, Song WM, Andhey PS, Swain A, Levy T, Miller KR, Poliani PL, Cominelli M, Grover S, Gilfillan S, Cella M, Ulland TK, Zaitsev K, Miyashita A, Ikeuchi T, Sainouchi M, Kakita A, Bennett DA, Schneider JA, Nichols MR, Beausoleil SA, Ulrich JD, Holtzman DM, Artyomov MN, Colonna M (2020) Human and mouse single-nucleus transcriptomics reveal TREM2-dependent and TREM2-independent cellular responses in Alzheimer's disease. Nature medicine 26 (1):131-142. doi:10.1038/s41591-019-0695-9

58. Yanaizu M, Washizu C, Nukina N, Satoh JI, Kino Y (2020) CELF2 regulates the species-specific alternative splicing of TREM2. Scientific reports 10 (1):17995. doi:10.1038/s41598-020-75057-x

59. Fineberg SK, Kosik KS, Davidson BL (2009) MicroRNAs potentiate neural development. Neuron 64 (3):303-309. doi:10.1016/j.neuron.2009.10.020

60. Gangaraju VK, Lin H (2009) MicroRNAs: key regulators of stem cells. Nature reviews Molecular cell biology 10 (2):116-125. doi:10.1038/nrm2621 
61. Latronico MV, Condorelli G (2009) MicroRNAs and cardiac pathology. Nature reviews Cardiology 6 (6):419-429. doi:10.1038/nrcardio.2009.56

62. Negrini M, Nicoloso MS, Calin GA (2009) MicroRNAs and cancer-new paradigms in molecular oncology. Current opinion in cell biology 21 (3):470-479. doi:10.1016/j.ceb.2009.03.002

63. O'Connell RM, Rao DS, Chaudhuri AA, Baltimore D (2010) Physiological and pathological roles for microRNAs in the immune system. Nature reviews Immunology 10 (2):111-122. doi:10.1038/nri2708

64. Subramanian S, Steer CJ (2010) MicroRNAs as gatekeepers of apoptosis. J Cell Physiol 223 (2):289298. doi:10.1002/jcp.22066

65. Lee YS, Dutta A (2009) MicroRNAs in cancer. Annual review of pathology 4:199-227. doi:10.1146/annurev.pathol.4.110807.092222

66. Calin GA, Croce CM (2006) MicroRNA signatures in human cancers. Nature reviews Cancer 6 (11):857866. doi:10.1038/nrc1997

67. Wang M, Qin L, Tang B (2019) MicroRNAs in Alzheimer's Disease. Frontiers in genetics 10:153. doi:10.3389/fgene.2019.00153

68. Henzinger H, Barth DA, Klec C, Pichler M (2020) Non-Coding RNAs and SARS-Related Coronaviruses. Viruses 12 (12). doi:10.3390/v12121374

69. Penghui Yang YZ, Jie Li, Chuanyu Liu, Linnan Zhu, Jie Zhang, Yeya Yu, Wen-Jing Wang, Guanglin Lei, Jin Yan, Fang Sun, Chengrong Bian, Fanping Meng, Zhe Xu, Changqing Bai, Beiwei Ye, Yuanyuan Guo, Liumei Shu, Xiaoju Yuan, Ning Zhang, Yuhai Bi, Yi Shi, Guizhen Wu, Shaogeng Zhang, George F. Gao, Longqi Liu, William J. Liu, Hai-Xi Sun (2021) Down-regulated miR-451a as a feature in plasma cfRNA landscape reveals regulatory networks of IL-6/IL-6R-associated cytokine storm in COVID-19 patients. Cellular \& Molecular Immunology. doi:https://doi.org/10.1038/s41423-021-00652-5

70. Driver JA, Beiser A, Au R, Kreger BE, Splansky GL, Kurth T, Kiel DP, Lu KP, Seshadri S, Wolf PA (2012) Inverse association between cancer and Alzheimer's disease: results from the Framingham Heart Study. BMJ 344:e1442. doi:10.1136/bmj.e1442

71. He Y, Lin J, Kong D, Huang M, Xu C, Kim TK, Etheridge A, Luo Y, Ding Y, Wang K (2015) Current State of Circulating MicroRNAs as Cancer Biomarkers. Clin Chem 61 (9):1138-1155.

doi:10.1373/clinchem.2015.241190

72. Musicco M, Adorni F, Di Santo S, Prinelli F, Pettenati C, Caltagirone C, Palmer K, Russo A (2013) Inverse occurrence of cancer and Alzheimer disease: a population-based incidence study. Neurology 81 (4):322-328. doi:10.1212/WNL.0b013e31829c5ec1 
73. Ou SM, Lee YJ, Hu YW, Liu CJ, Chen TJ, Fuh JL, Wang SJ (2013) Does Alzheimer's disease protect against cancers? A nationwide population-based study. Neuroepidemiology 40 (1):42-49.

doi:10.1159/000341411

74. Kinnunen PJ (2010) Cancer linked to Alzheimer disease but not vascular dementia. Neurology 75 (13):1215; author reply 1216. doi:10.1212/WNL.0b013e3181f001fb

75. Stánitz É, Juhász K, Gombos K, Gőcze K, Tóth C, Kiss I (2015) Alteration of miRNA expression correlates with lifestyle, social and environmental determinants in esophageal carcinoma. Anticancer Res 35 (2):1091-1097

76. Stánitz E, Juhász K, Tóth C, Gombos K, Natali PG, Ember I (2013) Evaluation of MicroRNA expression pattern of gastric adenocarcinoma associated with socioeconomic, environmental and lifestyle factors in northwestern Hungary. Anticancer Res 33 (8):3195-3200

\section{Tables}

Table 1 Baseline characters of the study population 


\begin{tabular}{|c|c|c|c|}
\hline Characteristics & $N C(n=62)$ & $A D(n=47)$ & $\mathrm{P}$ \\
\hline Age, mean (SD), years & $71.2(5.6)$ & $73.5(7.2)$ & 0.062 \\
\hline Female, n (\%) & $43(69.4)$ & $41(87.2)$ & 0.028 \\
\hline MMSE (SD) & $28.28(1.95)$ & $12.87(4.12)$ & $<0.001$ \\
\hline $\mathrm{BMI}, \mathrm{kg} / \mathrm{m} 2$ & & & $<0.001$ \\
\hline Underweight (<18.5) & $3(5.1)$ & $13(27.7)$ & \\
\hline Normal weight (18.5-23.9) & $34(57.6)$ & $26(55.3)$ & \\
\hline Overweight (24.0-27.9) & $19(32.2)$ & $8(17.0)$ & \\
\hline Obese (>=28) & $3(5.1)$ & $0(0.0)$ & \\
\hline Education & & & $<0.001$ \\
\hline No education & $15(24.6)$ & $46(97.9)$ & \\
\hline Elementary school & $15(24.6)$ & $1(2.1)$ & \\
\hline Middle school & $12(19.7)$ & $0(0.0)$ & \\
\hline High school & $6(9.8)$ & $0(0.0)$ & \\
\hline college & $13(21.3)$ & $0(0.0)$ & \\
\hline Current smoking & $4(6.5)$ & $12(25.5)$ & 0.012 \\
\hline Alcohol consumption & $9(14.5)$ & $7(14.9)$ & 0.928 \\
\hline Tea drinking & $18(29.0)$ & $2(4.3)$ & 0.002 \\
\hline Hypertension & $26(42.6)$ & $15(31.9)$ & 0.127 \\
\hline Depression & $0(0.0)$ & $24(51.1)$ & $<0.001$ \\
\hline Social connection & & & 0.002 \\
\hline Poor & $4(6.5)$ & $6(12.8)$ & \\
\hline Moderate & $23(37.1)$ & $31(65.9)$ & \\
\hline Rich & $35(56.5)$ & $10(21.3)$ & \\
\hline Leisure activity & $49(79.0)$ & $2(4.3)$ & $<0.001$ \\
\hline Physical activity & $60(96.8)$ & $43(91.5)$ & 0.476 \\
\hline Social connection, mean (SD) & $2.9(1.1)$ & $2.1(1.2)$ & $<0.001$ \\
\hline
\end{tabular}

Note: Data are presented as number (proportion \%). Missing data: None. 
Abbreviations: NC, normal cognition; AD, Alzheimer's disease; BMI, body mass index.

Chi-squared tests was used for statistical analysis of categoric variables by SPSS software.

Table 2 correlation analysis of specific expressed miRNA and lifestyle factors

\begin{tabular}{llll} 
& Canonical correlation analysis & F value & P value \\
\hline Education & 0.477 & 3.498 & 0.001 \\
\hline Smoke & 0.369 & 1.480 & 0.159 \\
\hline Tea & 0.261 & 1.194 & 0.316 \\
\hline Depression & 0.605 & 3.170 & $<0.001$ \\
\hline BMI & 0.221 & 0.713 & 0.661 \\
\hline Leisure activity & 0.411 & 5.036 & 0.001 \\
\hline Social network & 0.300 & 1.963 & 0.091
\end{tabular}

Abbreviations: BMI, body mass index.

Canonical correlation analyses were performed to determine any correlations between lifestyle factors and expressed miRNAs specified.

\section{Figures}




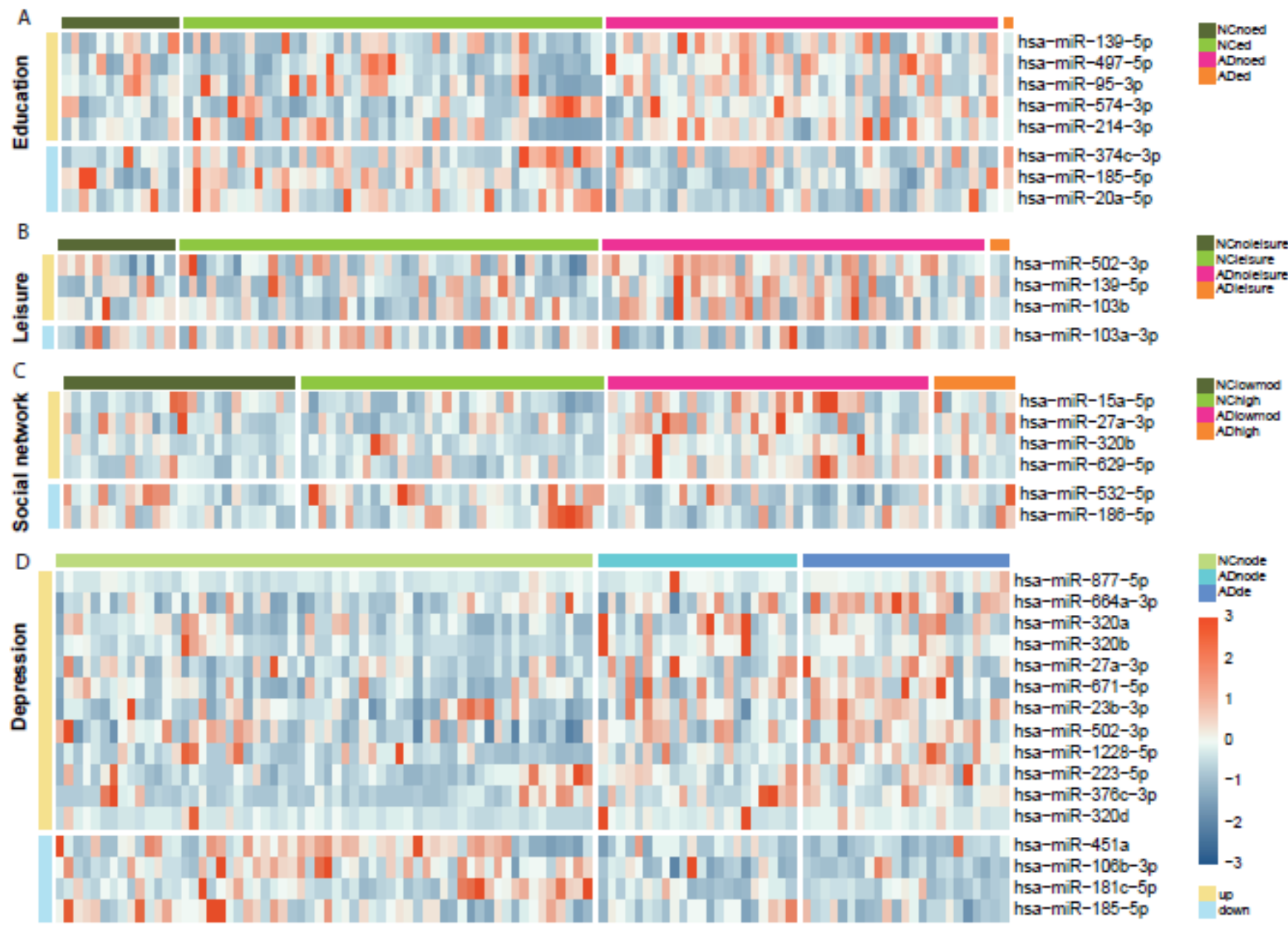

\section{Figure 1}

Heatmap of miRNAs for AD-related factors. A-D. Heatmap of miRNA expression level of all individuals with and without education (A), leisure activity (B), social connection (C), with and without depression (D). 
A

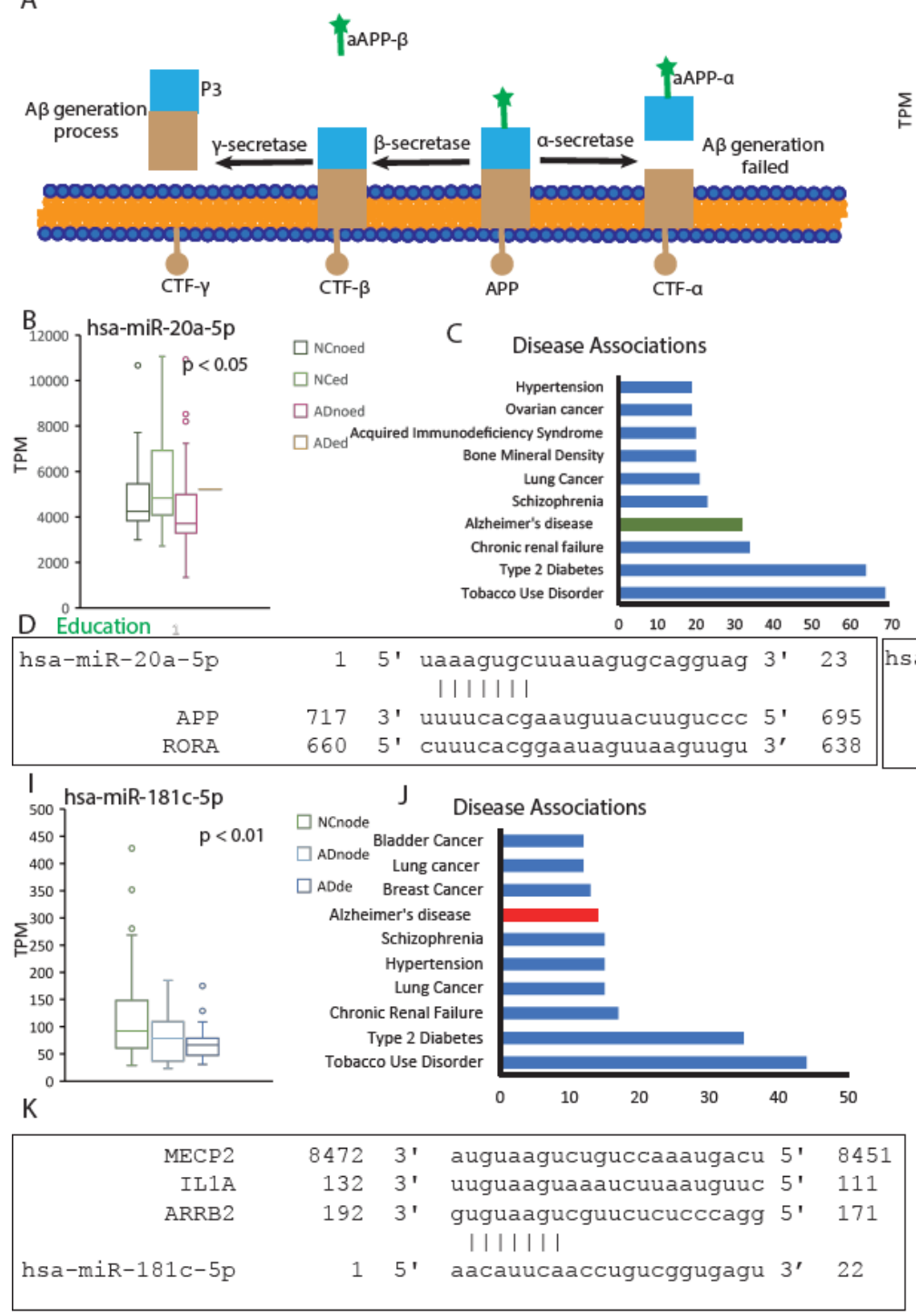

E hsa-miR-185-5p
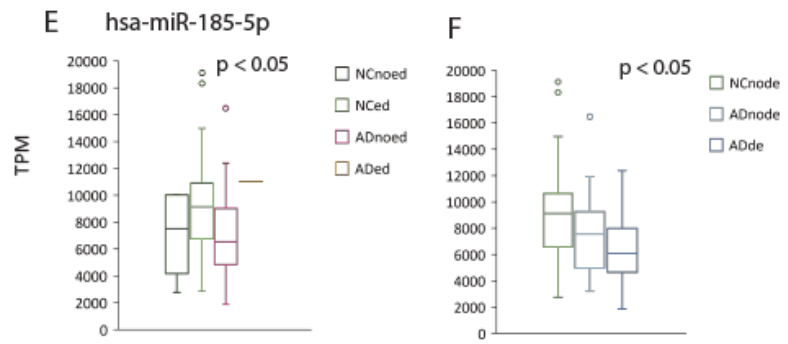

G Disease Associations

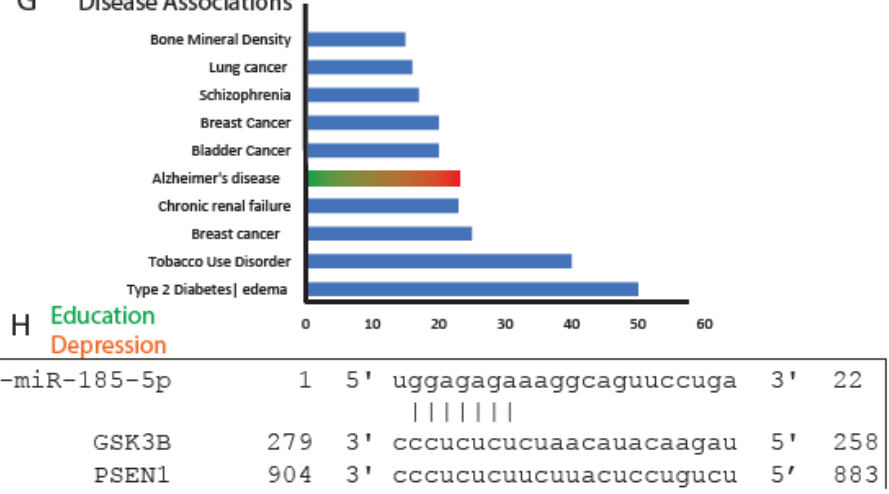

$\mathrm{L}$ PSEN1 $9043^{\prime}$ cccucucuucuuacuccugucu $5^{\prime} \quad 883$

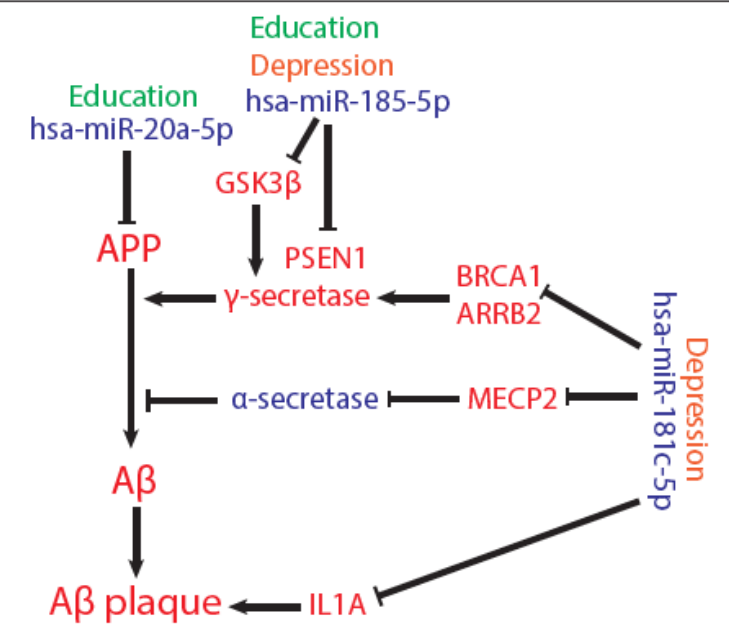

\section{Figure 2}

Education /depression and AD-related miRNAs were involved in AB generation. A - A schematic of the catalytic enzyme in APP; B - The relative expression level of hsa-miR-20a-5p categorized for education. NCnoed $=$ normal controls who had no education experience, $\mathrm{NCed}=$ normal controls who were educated, $A D$ noed $=A D$ patients who had no education experience, $A D e d=A D$ patients who were educated, $F(3$, $103)=3.676, P=0.0146$, one-way ANOVA followed by Tukey's Multiple Comparison Test; $C$ - Target enrichment analysis for hsa-miR-20a-5p; D - Predicted binding site for hsa-miR-20a-5p and its targets; E The relative expression level of hsa-miR-185-5p categorized for education, $F(3,103)=3.064, P=0.0314$, one-way ANOVA followed by Tukey's Multiple Comparison Test; $\mathrm{F}$ - The relative expression level of hsamiR-185-5p categorized for depression, $F(2,103)=4.238, P=0.0170$, one-way ANOVA followed by Tukey's Multiple Comparison Test. NCnode = normal controls who did not suffer from depression, $A D n o d e=A D$ patients who did not suffer from depression, $A D d e=A D$ patients who also suffered from depression; G - The relative expression level of hsa-miR-185-5p; H - Predicted binding site for hsa-miR-185- 
$5 p$ and its target; I - The relative expression level of hsa-miR-181c-5p categorized for depression, $F(2$, $103)=5.441, P=0.0057$, one-way ANOVA followed by Tukey's Multiple Comparison Test; $\mathrm{J}$ - Target enrichment analysis for hsa-miR-181c-5p; K - Predicted binding site for hsa-miR-181c-5p and its targets; $L$ - A summary of miRNAs and their targets that are involved in $A \beta$ generation process. Decreased expression level of miRNA and genes were marked as diamond blue color, increased expression level of miRNA and genes were marked as red color. Factor education was using dark green color, factor depression was using orange color.

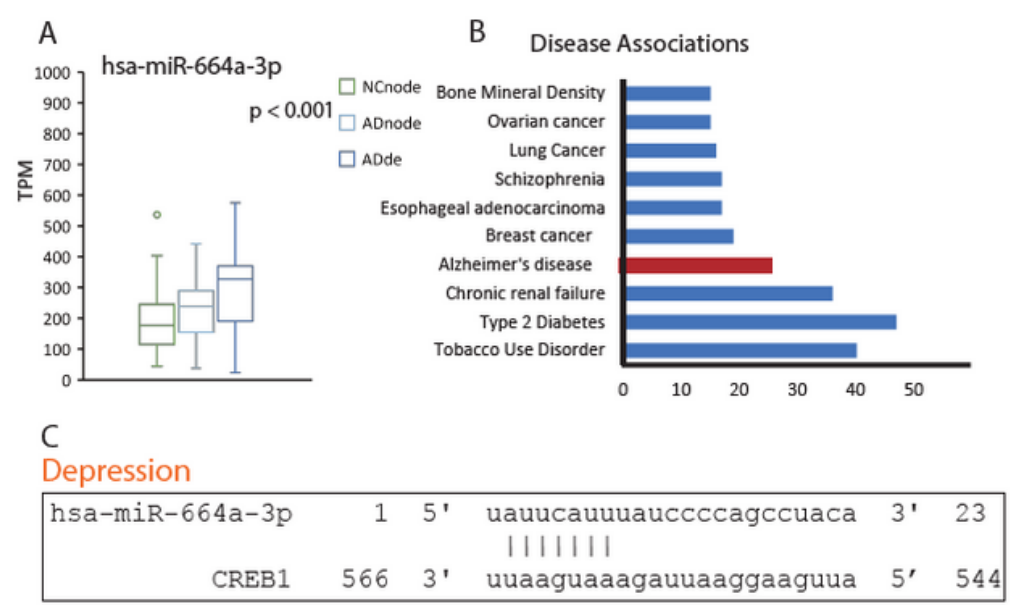

D

Depression

\begin{tabular}{|rrrrrr|}
\hline RORA & 1237 & $3^{\prime}$ & $\begin{array}{c}\text { uuguaaguguuucauuuaugaa } \\
\text { I|I||||| }\end{array}$ & $5^{\prime}$ & 1216 \\
hsa-miR-181c-5p & 1 & $5^{\prime}$ & aacauucaaccugucggugagu & $3^{\prime}$ & 22 \\
\hline
\end{tabular}

$E$

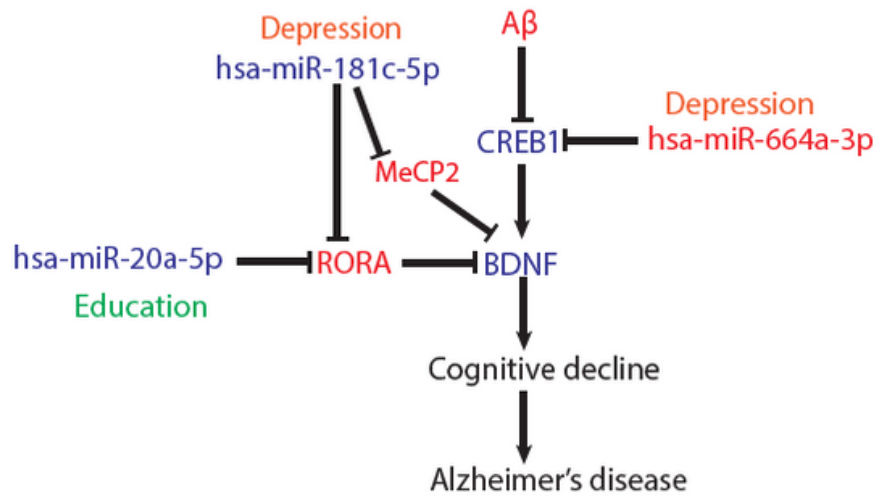

Figure 3

Education / depression- and AD-related miRNAs were involved in cognition decline. A - The relative expression level of hsa-miR-664a-3p categorized for depression, $F(2,103)=8.439, P=0.0004$, one-way ANOVA followed by Tukey's Multiple Comparison Test; B - Target enrichment analysis for hsa-miR-664a$3 p ; C$ - Predicted binding site for hsa-miR-664a-3p and its target; D - Predicted binding site for hsa-miR$181 c-5 p$ and its target; E - A summary of miRNAs and their targets that are involved in cognitive decline in $A D$. Decreased expression level of miRNA and genes were marked as diamond blue color, increased expression level of miRNA and genes were marked as red color. Factor education was using dark green color, factor depression was using orange color. 

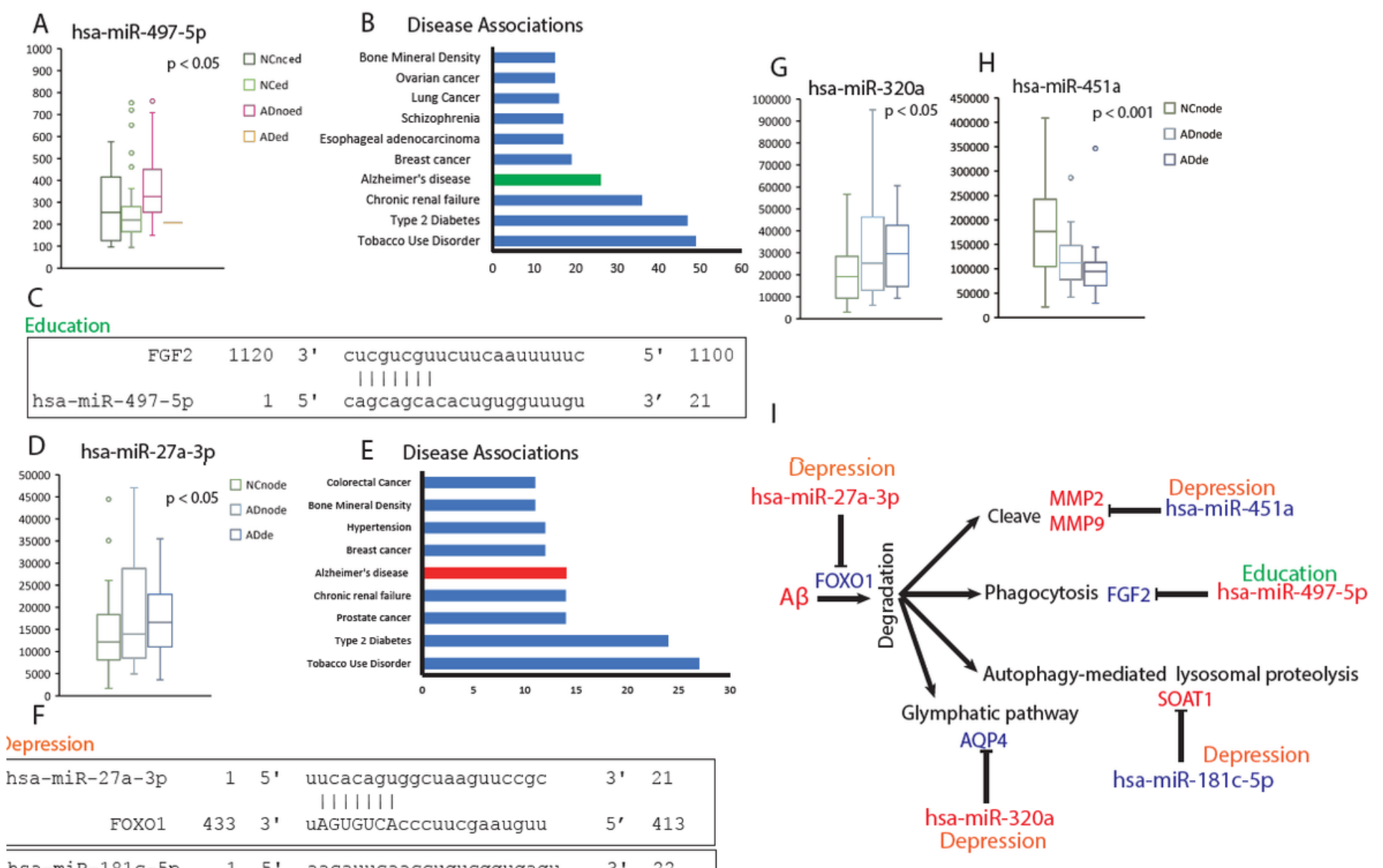

lepression

\begin{tabular}{rrrrrr|}
\hline hsa-miR-27a-3p & 1 & $5^{\prime}$ & $\begin{array}{c}\text { uucacaguggcuaaguuccgc } \\
\text { IIIIIII }\end{array}$ & $3^{\prime}$ & 21 \\
FOX01 & 433 & $3^{\prime}$ & uAGUGUCAcccuucgaauguu & $5^{\prime}$ & 413 \\
\hline \hline hsa-miR-181c-5p & 1 & $5^{\prime}$ & $\begin{array}{c}\text { aacauucaaccugucggugagu } \\
\text { IIIIIII }\end{array}$ & $3^{\prime}$ & 22 \\
SOAT1 & 3565 & $3^{\prime}$ & uuguaagugaaauaggaacuu & $5^{\prime}$ & 3544 \\
\hline
\end{tabular}

Figure 4

Education / depression- and AD-related miRNAs were involved in A $\beta$ clearance. A - The relative expression level of hsa-miR-497-5p categorized for education, $F(3,103)=3.500, P=0.0182$, one-way ANOVA followed by Tukey's Multiple Comparison Test; B - Target enrichment analysis for hsa-miR-497-5p; C Predicted binding site for hsa-miR-497-5p and its target; D - The relative expression level of hsa-miR-27a$3 p$ categorized for depression, $F(2,103)=3.338, P=0.0394$, one-way ANOVA followed by Tukey's Multiple Comparison Test; E - Target enrichment analysis for hsa-miR-27a-3p; F - Predicted binding site for hsa-miR-27a-3p, or hsa-miR-181c-5p and their targets; G - The relative expression level of hsa-miR320 a categorized for depression, $F(2,103)=4.605, P=0.0121$, one-way ANOVA followed by Tukey's Multiple Comparison Test; $\mathrm{H}$ - The relative expression level of hsa-miR-451a categorized for depression, $\mathrm{F}$ $(2,103)=9.595, \mathrm{P}=0.0002$, one-way ANOVA followed by Tukey's Multiple Comparison Test; I - A summary of miRNAs and their targets that are involved in cognitive decline in AD. Decreased expression level of miRNA and genes were marked as diamond blue color, increased expression level of miRNA and genes were marked as red color. Factor education was using dark green color, factor depression was using orange color. 

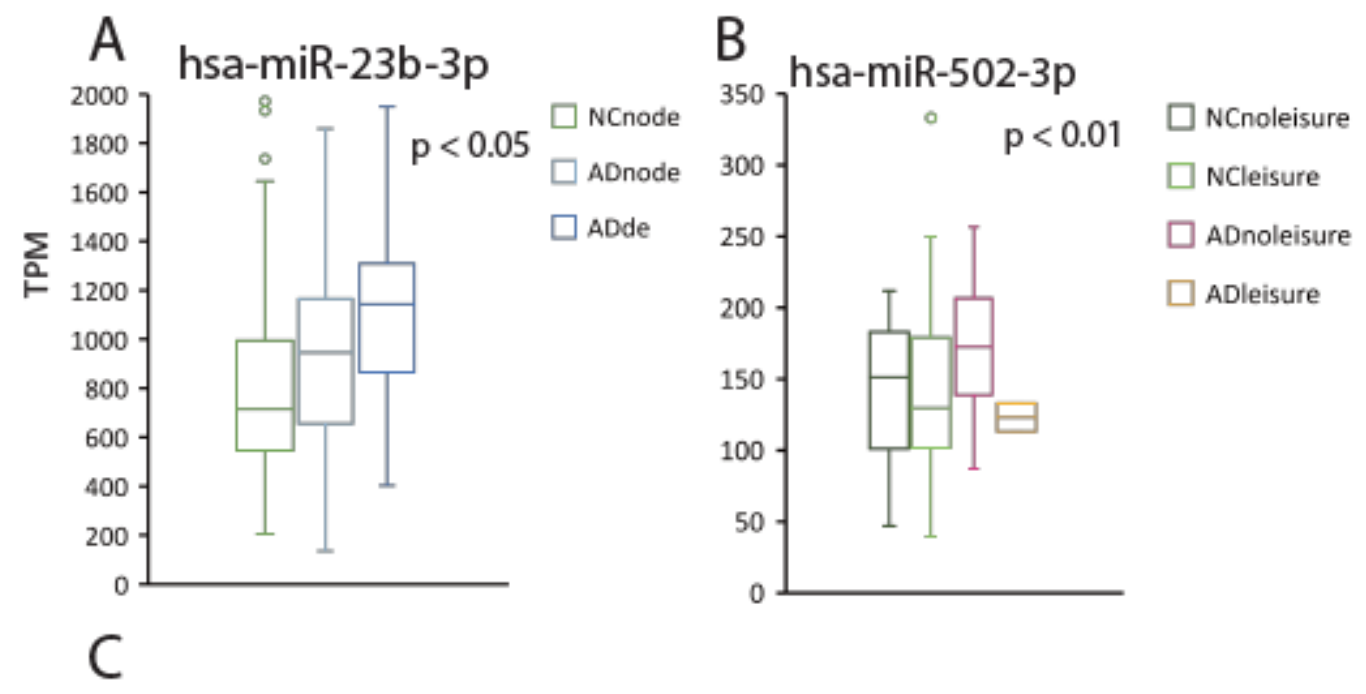

Depression

\begin{tabular}{|rrrrrr|}
\hline CELF2 & 4267 & $3^{\prime}$ & $\begin{array}{c}\text { uggagagaaaggcaguuccuga } \\
\text { IIIIIII }\end{array}$ & 4289 \\
hsa-miR-185-5p & 1 & $5^{\prime}$ & cccucucuuccccuuuaauugga & $3^{\prime}$ & 22 \\
\hline
\end{tabular}

\section{D}

Education

Depression

hsa-miR-185-5p $\longrightarrow$ CELF2 $\longrightarrow$ TREM2 in microglia

$A \beta$ accumulation

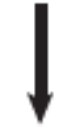

Disease-Activated Microglia

\section{Figure 5}

Other lifestyle- and AD-related miRNAs. A - The relative expression level of hsa-miR-23b-3p categorized for depression, $\mathrm{F}(2,103)=3.539, \mathrm{P}=0.0326$, one-way ANOVA followed by Tukey's Multiple Comparison Test; $B$ - The relative expression level of hsa-miR-502-3p categorized for leisure activities, $F(3,101)=2.979, P=$ 0.0350, one-way ANOVA followed by Tukey's Multiple Comparison Test. NCnoleisure $=$ normal controls who had no leisure activity, $\mathrm{NC}$ leisure $=$ normal controls who had leisure activity, $A D$ noleisure $=A D$ patients who had no leisure activity, ADleisure $=A D$ patients who had leisure activity; $C$ - Predicted binding site for hsa-miR-185-5p and its target; D - A summary of hsa-miR-185-5p and its targets that are involved in microglia response to $A \beta$ accumulation. Decreased expression level of miRNA and genes were marked as diamond blue color, increased expression level of miRNA and genes were marked as red color. Factor education was using dark green color, factor depression was using orange color.

\section{Supplementary Files}

This is a list of supplementary files associated with this preprint. Click to download.

- SupplementalTable1.docx 
- SupplementalTable2.docx

- SupplementalTable3.docx 